\title{
Noticias bio-bibliográficas
}

Roland Béhar es profesor en Estudios hispánicos en la École Normale Supérieure (París). Aunque sus investigaciones se centran principalmente en la literatura del Siglo de Oro español y su proyección europea, también trabaja sobre el modo en que la literatura latinoamericana se ha inspirado en la europea o ha sido percibida y traducida por ella. $\mathrm{Ha}$ editado, con Annick Louis, Lire Borges aujourd'hui. Autour de Ficciones et El Hacedor (París, Rue d'Ulm, 2016), con Mercedes Blanco y Jochen Hafner, Villes à la croisée des langues (XVle-XVIle siècles). Anvers, Hambourg, Milan, Naples et Palerme (Genève, Droz, 2018), con Laurence Breysse-Chanet e Ina Salazar, La parole impossible. Regards croisés autour de la traduction de César Vallejo, Marina Tsvetaeva et Paul Celan (París, Hermann, 2019), y con Gersende Camenen, Scènes de la traduction France-Argentine (París, Rue d’Ulm, 2020). En esta línea, ha publicado en 2020 un artículo sobre la primera recepción alemana de Jorge Luis Borges y, en 2021, la versión original, francesa, de À travers la Divine Comédie, De Francesca à Béatrice, de Victoria Ocampo (París, Rue D’Ulm).

Laurence Breysse-Chanet es egresada de la École Normale Supérieure (París). Se doctoró en 1992 con una tesis sobre la obra poética de Manuel Altolaguirre, bajo la dirección de Claude Esteban, en la Universidad de París-Sorbona. Obtuvo su HDR (Habilitación para supervisar investigaciones) en 2012, con La experiencia de la poesía en lengua española, su lectura crítica y traducción, en los siglos XX y XXI y con un libro inédito sobre la obra poética de Antonio Gamoneda. Actualmente es Catedrática de Literatura Española Contemporánea en Sorbonne Université. Codirige con Ina Salazar el eje LALE (Literatura de América Latina y España) del laboratorio CRIMIC, EA 2561 (2020) y el grupo PIAL (Poesía ibérica y latinoamericana) desde 2007. Su investigación se centra en la crítica de la poesía en lengua española (España y Latinoamérica), desde una complementariedad entre enfoques críticos y traducción. En 2010 obtuvo el Premio Nelly Sachs de traducción de poesía. Ha hecho varias coediciones de libros, numerosas traducciones (libros y reseñas). Entre sus obras, cabe destacar En la memoria del aire. Poesía y poética de Manuel Altolaguirre (Málaga, Centro Cultural Generación del 27, col. Estudios del 27, 2005) y Redes azules bajo los párpados. El pensamiento rítmico de Antonio Gamoneda (Préface de Miguel Casado, Paris, Éditions Hispaniques, 2019).

Gersende Camenen es profesora titular de literatura hispanoamericana y traducción en la Universidad Gustave-Eiffel. Trabaja sobre los imaginarios de la lengua y de la traducción, la historia de las traducciones y la recepción de la literatura latinoamericana en Francia. Ha publicado Roberto Arlt, écrire au temps de l'image (Rennes, PUR, 2012) y editado con Roland Béhar Scènes de la traduction France-Argentine (París, rue d'Ulm, 2020). Ha traducido al francés a varios autores como María Gainza, Federico Falco, Marcial Gala, Rodrigo Rey Rosa y Hernán Ronsino.

Stéphanie Decante es profesora titular en la Universidad Paris Nanterre donde enseña la literatura hispanoamericana y el cine. Es autora de una tesis doctoral sobre las políticas editoriales y la recepción crítica en el Chile de la transición a la democracia. En las revistas Mapocho, Crisol y Cahiers du genre ha dirigido publicaciones colectivas sobre literatura contemporánea, políticas de memoria y crítica literaria con perspectiva de género.

Ә Open Access. (c) 2022 Gustavo Guerrero and Gersende Camenenr, published by De Gruyter. (c) BY-NC-ND This work is licensed under the Creative Commons Attribution-NonCommercial-NoDerivatives 4.0 International License. https://doi.org/10.1515/9783110707557-013 
Está preparando un ensayo sobre "bovarismo" y crítica literaria femenina en el Chile de los años 1950. Es miembro de la red MEDET LAT. También se desempeña como traductora.

Liset Díaz Martínez es especialista en dialectología y en lexicografía hispanoamericana. Ha trabajado en proyectos de descripción léxica y de análisis metalexicográfico. Es doctora en Ciencias del lenguaje por la Universidad de Cergy-Pontoise y forma parte del laboratorio LT2D (Lexiques, textes, discours, dictionnaires). Actualmente sus investigaciones conciernen la metalexicografía, la obra del autor colombiano Gabriel García Márquez y las humanidades digitales. El estudio de los archivos editoriales y de la correspondencia, aplicando principios FAIR (Findable, Accessible, Interoperable, Reusable), también se incluyen en sus intereses de investigación. Su nuevo proyecto Mapping Gabo asocia estos trabajos usando el análisis de redes y las cartografías digitales. Pertenece al equipo editorial del Museo virtual de los diccionarios y es redactora asociada de la revista ELA (Estudios de lingüística aplicada).

Gustavo Guerrero es profesor de literatura y cultura hispanoamericanas contemporáneas en CY Paris Cergy Université. Su libro más reciente es Paisajes en movimiento, literatura y cambio cultural entre dos siglos (Buenos Aires, Eterna Cadencia, 2018). También ha coeditado recientemente las obras colectivas World Editors Dynamics of Global Publishing and the Latin American Case between the Archive and the Digital Age (Berlín, De Gruyter, 2021) en colaboración con Gesine Mueller y Benjamin Loy; Literatura latinoamericana mundial: dispositivos y disidencias (Berlín, De Gruyter, 2019) en colaboración con Gesine Mueller, Benjamin Loy y Jorge Locane; y Cámara de eco, homenaje a Severo Sarduy (México, Fondo de Cultura Económica, 2018) en colaboración con Catalina Quesada-Gómez. Fue profesor invitado del Programa de Estudios Latinoamericanos de la Universidad de Princeton en 2009 y 2010, de la Universidad de Cornell en 2014 y de la Universidad de Berna en 2018. Actualmente dirige el proyecto interuniversitario Mediación editorial, difusión y traducción de la literatura latinoamericana en Francia (MEDET LAT) en la École Normale Supérieure (París) y es coresponsable de los proyectos Poetry in Notions: Online Compendium of Lyric Poetry (2020-24) financiado por el Fondo Nacional Suizo de Investigación Científica (FNS) y de Infrastructures of Cultural Production, Literature and Cinema, between France and Latin America financiado por la Iniciativa de Excelencia Paris-Seine (2021-2023).

Nataly Jiménez Melo es Máster en Literaturas Francesa y Comparada de la Universidad de Rouen, cursa un doctorado en la Universidad de Caen- Normandía sobre las estrategias de difusión y la promoción editorial de Sobre héroes y tumbas, Cien años de Soledad y El mundo alucinante en Francia (1967-1969). Actualmente es lectora en el Departamento de Estudios Iberoamericanos de esta misma universidad.

Annick Louis es profesora en la Universidad de Franche-Comté (Francia). Fue Visiting Professor en la Universidad de Yale (1999-2000), y becaria de la Fundación Alexander von Humboldt (2000-2002, 2010). Especialista de la obra de Jorge Luis Borges, de literatura argentina e hispanoamericano y de teoría literaria, su trabajo actual se orienta hacia la epistemología de la literatura. Sobre Borges ha publicado: Jorge Luis Borges. Obra y maniobras (2014), y Borges ante el fascismo (2007). Su último libro es L'invention de Troie. Les vies rêvées de Heinrich Schliemann (2020). Ha traducido al francés a Quevedo y a María Zambrano. 
Márcia Valéria Martinez de Aguiar es traductora, profesora de la Universidad Federal de São Paulo y miembro del Grupo de Investigación Brasil-Francia de la IEA-USP. Su investigación se centra en la traducción y recepción de la obra de João Guimarães Rosa en Francia.

En particular, editó y anotó la correspondencia de este autor con su traductor francés Jean-Jacques Villard. Como parte de su labor como traductora, ha traducido numerosas obras de literatura y ciencias humanas de diferentes autores, como Voltaire, Roland Barthes, Merleau-Ponty y Paul Ricœur.

Florence Olivier es catedrática de Literatura Comparada en la Universidad Sorbonne Nouvelle. Especialista en literatura latinoamericana y traductora, es autora de Carlos Fuentes o la imaginación del otro (Editorial de la Universidad Veracruzana, 2007) / Carlos Fuentes ou l'imagination de l'autre (Aden, Londres, 2009) y Poesía + novela = poesía. La apuesta de Roberto Bolaño (Editorial de la Universidad Veracruzana, 2015) / Sous le roman, la poésie. Le défi de Roberto Bolaño (Paris, Hermann, 2016). Codirigió con Françoise Moulin-Civil y Teresa Orecchia-Havas La littérature latino-américaine au seuil du XXI siècle. Un parnasse en éclats (Aden, Londres, 2013), volumen que reúne las contribuciones de un coloquio de Cerisy. Codirige la revista América-Cahiers du Criccal publicada por las Presses de la Sorbonne Nouvelle.

Roberto Pareja es investigador asociado a MEDET LAT. Como crítico cultural ha publicado Entre caudillos y multitudes. Modernidad estética y esfera pública en Bolivia, siglos XIX y XX (Madrid/Frankfurt, Iberoamericana/Vervuert, 2014) y, en coautoría, Latin American Marxisms in context: past and present (Newcastle upon Tyne, Cambridge Scholars Publishing, 2019), además de artículos sobre la cinematografía de Jorge Ruiz y sobre la historia intelectual de Bolivia y Perú. Como humanista digital ha trabajado en proyectos sobre la historia social peruana y el análisis de las redes de clubes provincianos en Lima a principios del siglo XX y, actualmente, colabora en la finalización del proyecto MEDET LAT. Ha obtenido un doctorado en Literatura Latinoamericana y Estudios Culturales de Georgetown University y una maestría en Information Studies de Mcgill University. Entre sus proyectos actuales están la investigación de las redes de mediación editorial de la literatura latinoamericana a nivel global a través de los metadatos bibliográficos de la literatura crítica, además del estudio de la red ego-centrada del escritor boliviano Jaime Sáenz.

Michel Riaudel es profesor responsable de la sección de estudios de habla portuguesa de la Universidad de la Sorbona y miembro del CRIMIC. Explora nociones como intertextualidad, traducción, recepción, transferencia, así como la relación entre literatura e historia, y los "regímenes de lectura". Sus obras se han centrado en la literatura brasileña y las circulaciones literarias Francia / Brasil, la poesía marginal carioca, el modernismo, Jules Verne; y más recientemente sobre las metamorfosis del personaje de Caramuru: Caramuru, un héroe brasileño entre el mito y la historia (París, ediciones Petra, 2017). Dirigió el catálogo bibliográfico Francia-Brasil (ADPF, 2005), El cuerpo y sus traducciones (con Camille Dumoulié: Desjonquères, 2008) y el dossier de literatura brasileña contemporánea para la revista Europa (con Pierre Rivas, noviembre-diciembre de 2005). Ha traducido obras de Modesto Carone, José Almino, Milton Hatoum, Luiz Schwarcz, Ana Cristina Cesar y João Guimarães Rosa, entre otros. 
Ina Salazar es catedrática de literatura hispanoamericana en la Universidad de la Sorbona. Su actividad como investigadora se centra en la poesía hispanoamericana moderna y contemporánea y más precisamente en la peruana. Ha publicado artículos en diversas revistas de Francia, Estados Unidos y Perú, en torno a la obra de poetas mayores de la poesía peruana del siglo XX como César Vallejo, Carlos Oquendo de Amat, Martín Adán, Emilio Adolfo Westphalen, Blanca Varela, Jorge Eduardo Eielson o Carlos Germán Belli, interesándose asimismo en los procesos y rupturas que llevan a la poesía peruana actual. Últimamente ha publicado las monografías La poesía ante la muerte de Dios. César Vallejo, Jorge Eduardo Eielson, Blanca Varela (Lima, PUCP, 2015), y La substancia humana de la poesía, aproximaciones a la obra poética de César Vallejo (París, PUF/CNED, 2016). Como poeta ha publicado En tregua con la vida (Lima, Campodónico editores, 2002), y En las aguas de la noche (Lima, Paracaídas editores, 2016). 